\title{
High performance of chlorophyll- $a$ prediction algorithms based on simulated OLCI Sentinel-3A bands in cyanobacteria-dominated inland waters
}

\author{
Fernanda Sayuri Yoshino Watanabe ${ }^{\mathrm{a}, *}$, Enner Alcântara ${ }^{\mathrm{b}}$, José Luiz Stech ${ }^{\mathrm{c}}$ \\ ${ }^{a}$ Department of Cartography, Universidade Estadual Paulista (UNESP), Rua Roberto Simonsen, 305, Presidente Prudente, SP 19060-900, Brazil \\ ${ }^{\mathrm{b}}$ Department of Environmental Engineering, Universidade Estadual Paulista (UNESP), Rodovia Presidente Dutra, Km 137,8, Eugenio de Melo, \\ 12247-004 São José dos Campos, SP, Brazil \\ ${ }^{\mathrm{c}}$ Remote Sensing Division, Instituto Nacional de Pesquisas Espaciais (INPE), Avenida dos Astronautas, 1758, São José dos Campos, SP 12227-010, Brazil
}

Received 15 December 2017; received in revised form 6 April 2018; accepted 19 April 2018

Available online 1 May 2018

\begin{abstract}
In this research, we have investigated whether the chlorophyll- $a$ (chl $a$ ) retrieval algorithms based on OLCI Sentinel-3A bands are suitable for cyanobacteria-dominated waters. Phytoplankton assemblages model optical properties of the water, influencing the performance of bio-optical algorithms. Understanding these processes is important to improve the prediction of photoactive pigments in order to use them as a proxy for trophic state and harmful algal bloom. So that, both empirical and semi-analytical approaches designed for different inland waters were tested. In addition, empirical models were tuned based on dataset collected in situ. The study was conducted in the Funil hydroelectric reservoir, where chl $a$ ranged from 2.33 to $208.68 \mathrm{mg} \mathrm{m}^{-3}$ in May 2012 (austral fall) and 4.37 to $306.03 \mathrm{mg} \mathrm{m}^{-3}$ in October 2012 (austral spring). OLCI Sentinel-3A bands were tested in existing algorithms developed for other sensors and new band combinations were compared to analyze the errors produced. Normalized Difference Chlorophyll Index (NDCI) exhibited the best performance, with a Normalized Root Mean Square Error (NRMSE) of 9.30\%. Result showed that wavelength at $665 \mathrm{~nm}$ is adequate to estimate chl $a$, although the maximum pigment absorption band is shifted due to phycocyanin fluorescence at approximately 650 nm. (C) 2018 COSPAR. Published by Elsevier Ltd. All rights reserved.
\end{abstract}

Keywords: Harmful algal bloom; Case-2 waters; Remote sensing; Water quality

\section{Introduction}

The wastewater discharge in freshwater bodies causes unbalance in aquatic ecosystem such as eutrophication and fish kills (Anderson et al., 2002). Eutrophication leads to growing the primary productivity (Anderson et al., 2002), which may become the water inappropriate for multiple uses such as drinking water supply. In reservoirs, the eutrophication may be more intense due to water level control, increasing the water residence time and providing

\footnotetext{
* Corresponding author.

E-mail address: fernanda@fct.unesp.br (F.S.Y. Watanabe).
}

nutrients for longer time (Soares et al., 2008, 2012). In these condition it is common to detect harmful algal blooms and, therefore, their monitoring is important to keep the quality of the aquatic life and public health.

In natural waters, phytoplankton assemblage is composed for different species, but there can be dominance of specific specie depending on the aquatic system conditions. Cyanobacteria dominance is commonly associated with high retention time (Carvalho et al., 2011; Romo et al., 2013), water column mixing in tropical waters (Calijuri and dos Santos, 1996) and high trophic state (Calijuri and dos Santos, 1996; Ogashawara et al., 2013; Mishra et al., 2014; Costa et al., 2014). Variations in phytoplankton communities 
consequently change the optical properties (Richardson, 1996; Ruiz-Verdú et al., 2008). Ruiz-Verdú et al. (2008) compared the absorption coefficients of cyanobacteria, chlorophyta and diatomaceous and showed that the maximum cyanobacteria absorption peak in the red region is shifted into longer wavelengths, probably caused by phycocyanin fluorescence at approximately $650 \mathrm{~nm}$ (Schalles and Yacobi, 2000).

Chlorophyll- $a$ (chl $a$ ) content, pigment found in all phytoplankton species, has been used as proxy of their biomass and, due to its photoactive characteristic remotely sensed imagery becomes a powerful tool to monitor harmful algal blooms. Several bio-optical algorithms have been designed to retrieve the chl $a$ concentration in inland waters adopting different band combinations (Dekker, 1993; Dall'Olmo et al., 2003; Mishra and Mishra, 2012). In inland waters, red and near-infrared (NIR) bands are widely used in order to reduce the interference of other optically significant constituents (OSCs) (Gilerson et al., 2010).

Different remote sensors have been tested to achieve the best performance, such as Landsat (Watanabe et al., 2015; Bernardo et al., 2017), MODIS (Carder et al., 1999; Mishra and Mishra, 2010), MERIS (Moses et al., 2009; Gilerson et al., 2010; Gurlin et al., 2011; Mishra and Mishra, 2012) and hyperspectral systems (Olmanson et al., 2013; Tan et al., 2015). However, in general, the phytoplankton species are not always considered in parameterizing chl $a$ prediction algorithms. Therefore, we hypothesized that performance of NIR-red algorithms could be hampered in cyanobacteria-dominated inland waters due to shifting of the absorption feature of chl $a$ in the red light region caused by phycocyanin fluorescence.

With the launch of the Ocean and Land Colour Instrument (OLCI) onboard Sentinel-3A. there is a new alternative for mapping chl $a$ in inland waters and, therefore, the hypothesis might be responded. The aim of this work was to investigate if phycocyanin fluorescence in the red spectral region impairs the performance of chl $a$ prediction algorithms based on OLCI Sentinel-3A bands in the red and NIR spectral region. In turn, the specific objectives were (a) to evaluate existing empirical NIR-red algorithms and semi-analytical algorithms based on absorption at 665 $\mathrm{nm}$; (b) to calibrate NIR-red algorithms considering the dataset acquired in a cyanobacteria-dominated aquatic system; (c) to design a chl $a$ prediction algorithm based on phycocyanin feature at $620 \mathrm{~nm}$; and (d) to compare the performance of all tested algorithms in estimating chl $a$. We expected that the findings of this study could be useful to understand the influence of the spectral features of phytoplankton pigments in estimating chl $a$ content and therefore to monitoring the trophic status.

\section{Data and methods}

\subsection{Study area}

The study area was the Funil hydroelectric reservoir (FHR, 22 $33^{\prime} 48.97^{\prime \prime} \mathrm{S}, 44^{\circ} 36^{\prime} 13.24^{\prime \prime} \mathrm{W}$ ), located in the
Paraíba do Sul River, in the southern Rio de Janeiro State, Brazil (Fig. 1). Operating since 1969, the FHR has $40 \mathrm{~km}^{2}$ flooded area and $890 \times 10^{6} \mathrm{~km}^{3}$ volume, with an average retention time of 32 days. Paraíba do Sul River is located in a populous and industrialized region, responsible for a high sewage discharge, causing eutrophication in the reservoir (Soares et al., 2012). Eutrophication and retention time have been pointed as responsible for intense cyanobacteria blooms in the Funil reservoir (Rangel et al., 2012; Soares et al., 2012; Ogashawara et al., 2013).

\subsection{Field sampling}

Two field campaigns were conducted on May 20-22, 2012 (austral autumn and period of high water level) and September 2-4, 2012 (austral spring and period of low water level). In May 19 samples were collected, while 10 samples were acquired in September. Location of the sampling points at each field campaign is shown in Fig. 1c. Water samples were collected to estimate the chl $a$ concentration (Nusch, 1980) and suspended material (total, inorganic and organic) (APHA, 1998) in the laboratory.

Field spectroscopy data were measured using two RAMSES spectroradiometers (TriOS, Rastede, Germany), acquiring measurements of radiance (ARC-VIS sensor, with $7^{\circ}$ field of view) and irradiance (ACC-VIS sensor, with cosine collector). The radiometers work between 320 and $950 \mathrm{~nm}$, with a spectral sampling of $3.3 \mathrm{~nm}$ and spectral accuracy of $0.3 \mathrm{~nm}$. These data were used to calculate the remote sensing reflectance $\left(R_{\mathrm{rs}}\right.$, in $\left.\mathrm{sr}^{-1}\right)$ according to Mobley (1999). OLCI Sentinel-3A bands were simulated from in situ $R_{\mathrm{rs}}$ and spectral response function of the sensor as:

$R_{r s}^{O L C I}\left(\lambda_{k}\right)=\frac{\int_{\lambda_{i}}^{\lambda_{j}} S(\lambda) R_{r s}(\lambda)}{\int_{\lambda_{i}}^{\lambda_{j}} S(\lambda)}$

where $R_{R s}^{O L C I}$ stands for the remote sensing reflectance convoluted from OLCI spectral bands; $\lambda_{i}$ and $\lambda_{j}$ are the lower and upper limit of the band $\lambda_{k}$, respectively; and $S(\lambda)$ is the spectral response function of the $i$ th spectral band of OLCI.

\subsection{Chlorophyll-a model calibration and validation}

Semi-empirical NIR-red based algorithms and semianalytical using data in the red spectral region were tested adopting the datasets collected in May and September 2012. The NIR-red algorithms were adopted to estimate chl $a$ concentration: two-band simple ratio (2B; Dekker 1993), three-band (3B; Dall'Olmo et al., 2003), and Normalized Difference Chlorophyll Index (NDCI; Mishra and Mishra, 2012). Table 1 shows the structure for each band algorithm. Bands 4, 5 and 6 (central wavelength at $\lambda_{1}=665 \mathrm{~nm}, \lambda_{2}=708.75 \mathrm{~nm}$ and $\lambda_{3}=753.75 \mathrm{~nm}$, respectively) from OLCI Sentinel 3A were adopted in the models. 

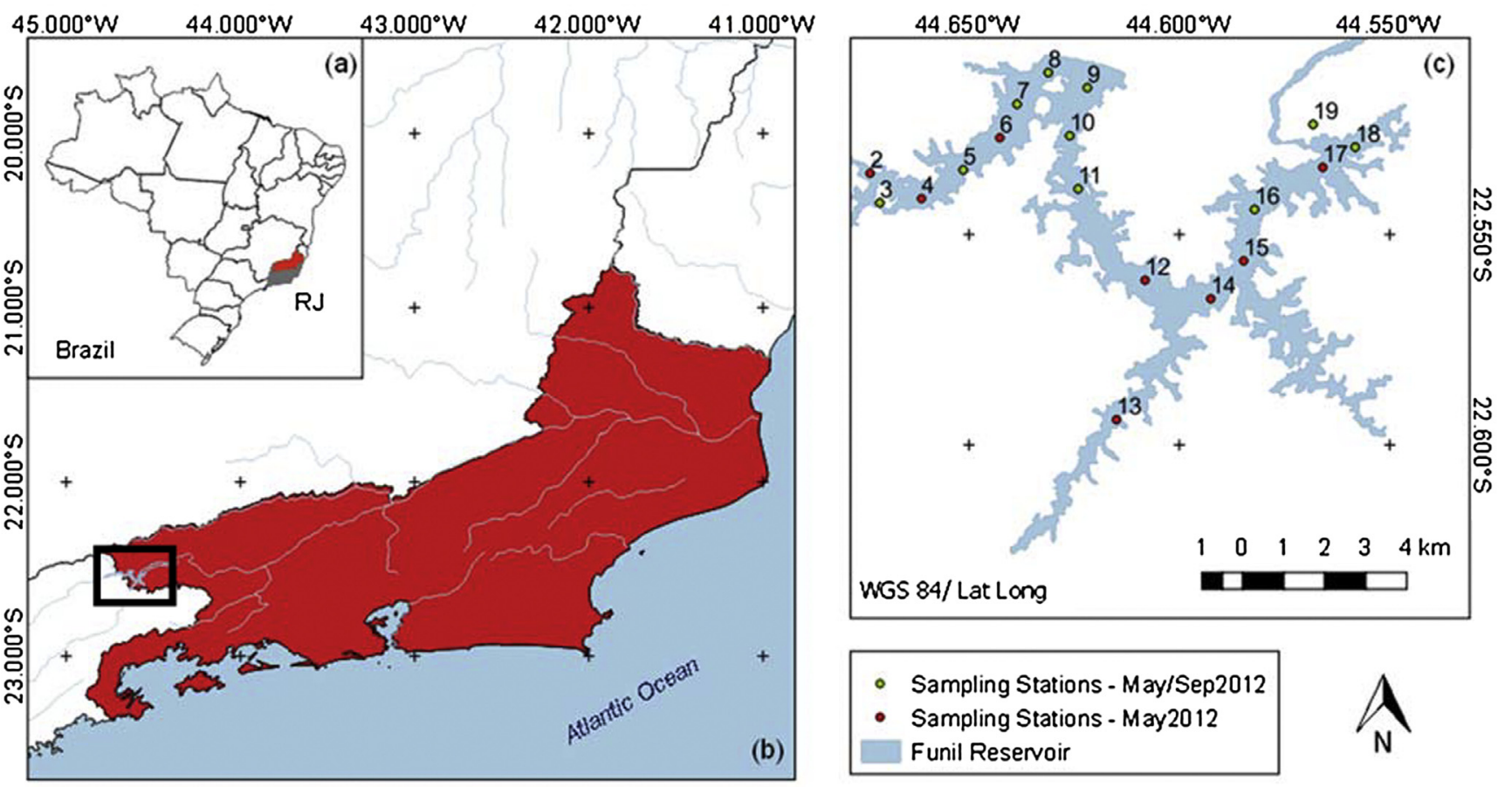

Fig. 1. Location of the study area, showing (a) its position in Brazil and (b) Rio de Janeiro state and the distribution of sampling stations in the (c) Funil hydroelectric reservoir, located in Paraíba do Sul River.

These algorithms were chosen because they were parameterized for productive waters.

Two semi-analytical (SA) algorithms based on $665 \mathrm{~nm}$ (Gons et al., 2008; Gilerson et al., 2010) were tested to estimate chl $a$ concentration. Such algorithms request values of the phytoplankton pigment absorption coefficient $\left(a_{\varphi}\right)$ and/or non-water constituent absorption coefficient $\left(a_{\mathrm{t}-\mathrm{w}}\right)$, but which neither were collected during the fieldworks nor estimated in laboratory. Therefore, the Inherent optical properties Inversion Model of Inland Waters (IIMIW) proposed by Li et al. (2013) was used to retrieve the absorption coefficients required in semi-analytical modeling. IIMIW (Li et al. 2013) was selected because it was parameterized based on a wide dataset from four different freshwaters. In addition, chl $a$ range used by them cover concentration of chl $a$ found in our study area.
Table 1 shows the calibrations tested in this study and the selection were based on researches conducted in turbid productive waters. Existing calibrations were tested both band algorithms (Moses et al., 2009; Gilerson et al., 2010; Mishra and Mishra, 2012; Gurlin et al., 2011) and semi-analytical models (Ritchie, 2008; Gons et al., 2008). Besides calibrations proposed for other aquatic systems we recalibrated the algorithms considering dataset collected in May 2012. The adjustment was conducted using the least square method, attempting linear and polynomial fits.

In cyanobacteria-dominated waters it is expected that phycocyanin and chl $a$ are highly correlated and consequently with the phytoplankton biomass (Shi et al., 2015). Therefore, although the absorption feature around $620 \mathrm{~nm}$ is associated with phycocyanin pigment and not

Table 1

NIR-red algorithms and calibrations applied to estimate chl $a$ concentration.

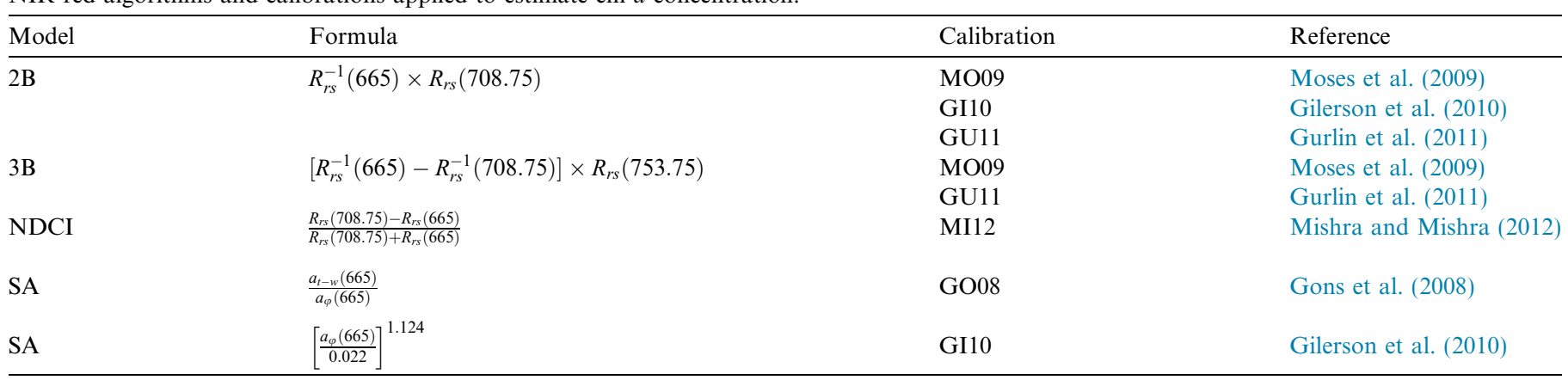


chl $a$, new algorithms were also parameterized replacing $\lambda_{1}$ $=665 \mathrm{~nm}$ for $620 \mathrm{~nm}$ in 2B and NDCI algorithms, and calibrated using the dataset collected in both field surveys in the FHR. The new algorithms were labeled as M2B and MNDCI, where $M$ means modified. The adjustment of the algorithms was based on the least square method (linear and polynomial fits).

The assessment of all the algorithms was conducted using the following statistical metrics: Root Mean Square Error (RMSE) Normalized Root Mean Square Error (NRMSE) and determination coefficient $\left(\mathrm{R}^{2}\right)$. The September dataset was used in assessment of all algorithms tested. Additionally, the validation of the algorithms calibrated

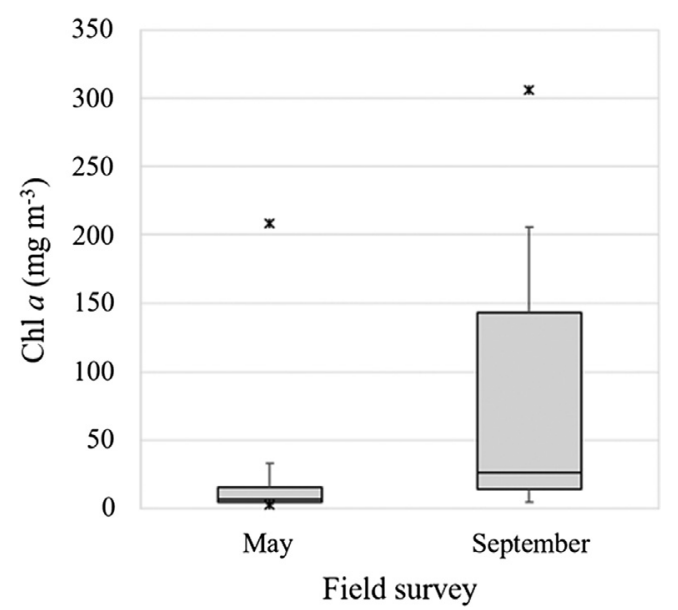

Fig. 2. Box-plot of chl $a$ concentration for data collected in May and September 2012.
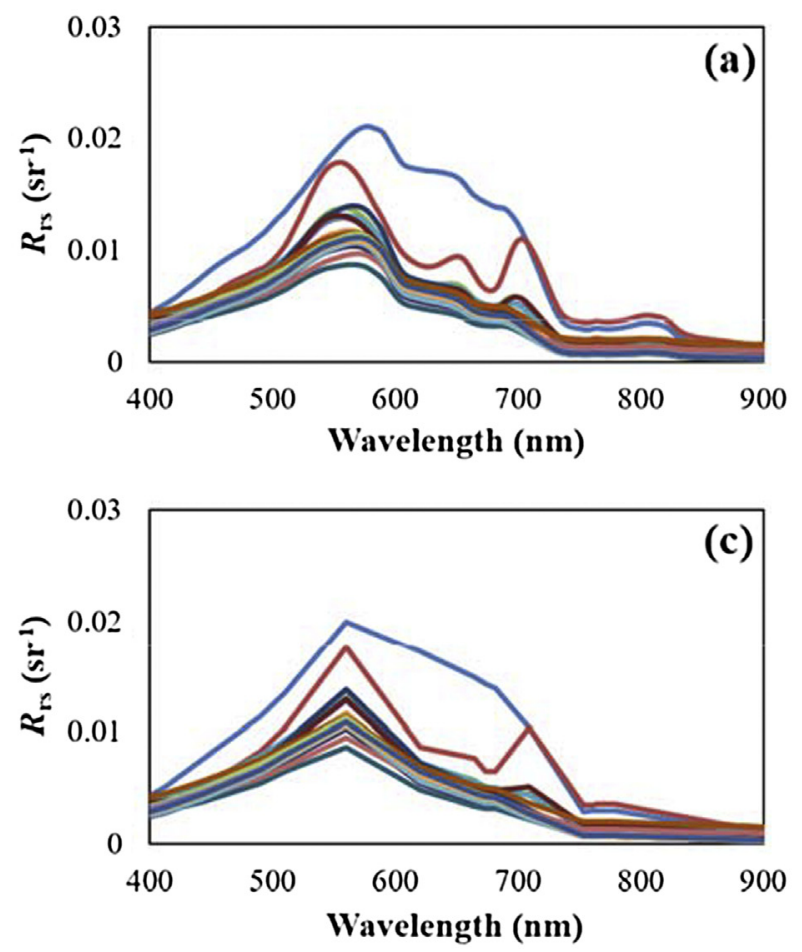

using the FHR dataset was based on Leave-One-Out Cross Validation (LOOCV). Such validation statistical technique is rather useful and widely used in cases where the sampling size is limited.

\section{Results and discussion}

\subsection{Application of existing bio-optical models}

The Funil reservoir exhibited a large variability of chl $a$ concentrations ranging from 2.33 to $208.68 \mathrm{mg} \mathrm{m}^{-3}$ in May and 4.37 to $306.03 \mathrm{mg} \mathrm{m}^{-3}$ in September. Meanwhile, variation of the total suspended material (TSM) was from 3.38 to $64 \mathrm{mg} \mathrm{L}^{-1}$, with predominance of organic fraction (average of $83 \%$ ), and, therefore, TSM was mainly composed of phytoplankton biomass. Fig. 2 shows the chl a content variation observed from May to September 2012.

In situ $R_{\mathrm{rs}}$ spectra and simulated bands are shown in Fig. 3. Analyzing the in situ $R_{r s}$ spectra the phycocyanin features associated with absorption at $620 \mathrm{~nm}$ and fluorescence at $650 \mathrm{~nm}$ were quite remarkable (Fig. 3a and b), whilst the first feature is realized at OLCI Sentinel-3A simulated spectra and the second one is lost (Fig. 3c and d). In addition, features of chl $a$ absorption and particles reflectance around $680 \mathrm{~nm}$ and $715 \mathrm{~nm}$, respectively, are more highlighted in September dataset.

Fig. 4 shows the validation results obtained by NIR-red algorithms and IIWIM-based semi-analytical models.

Among the existing 2B algorithms, MO09 calibration showed the best performance (NRMSE of 13.65\% and $\left.\mathrm{R}^{2}=0.92\right)$, followed by GI10 (NRMSE $=19.77 \%$ and
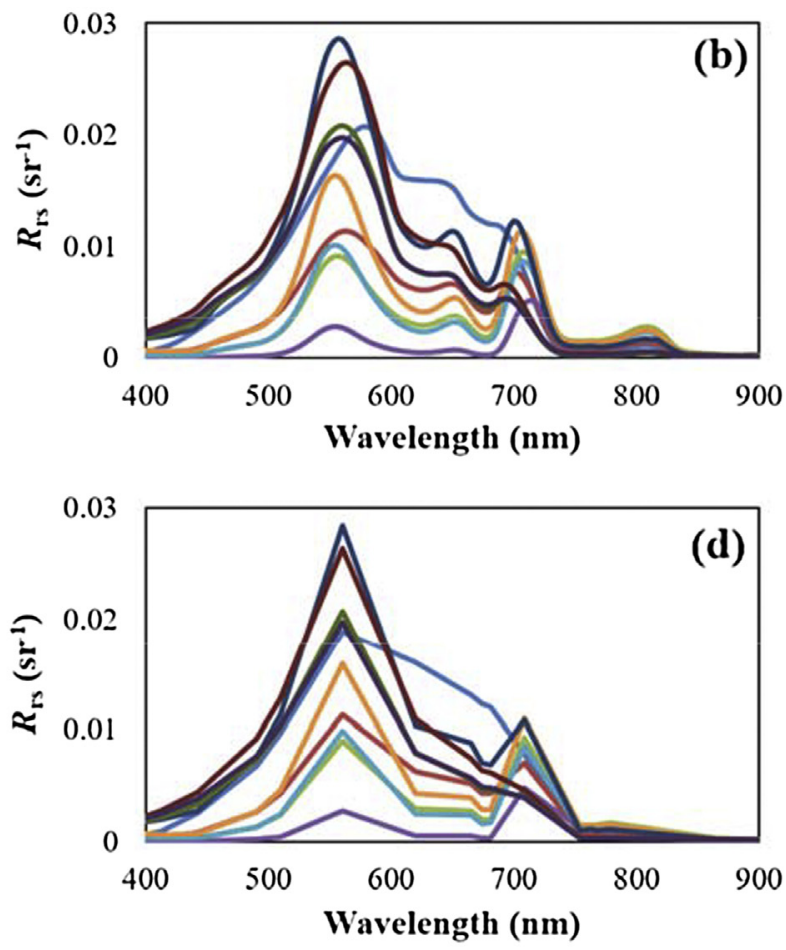

Fig. 3. $R_{\mathrm{rs}}$ spectra collected in situ in (a) May and (b) September 2012 and their respective simulated OLCI Sentinel-3A bands (c and d). 

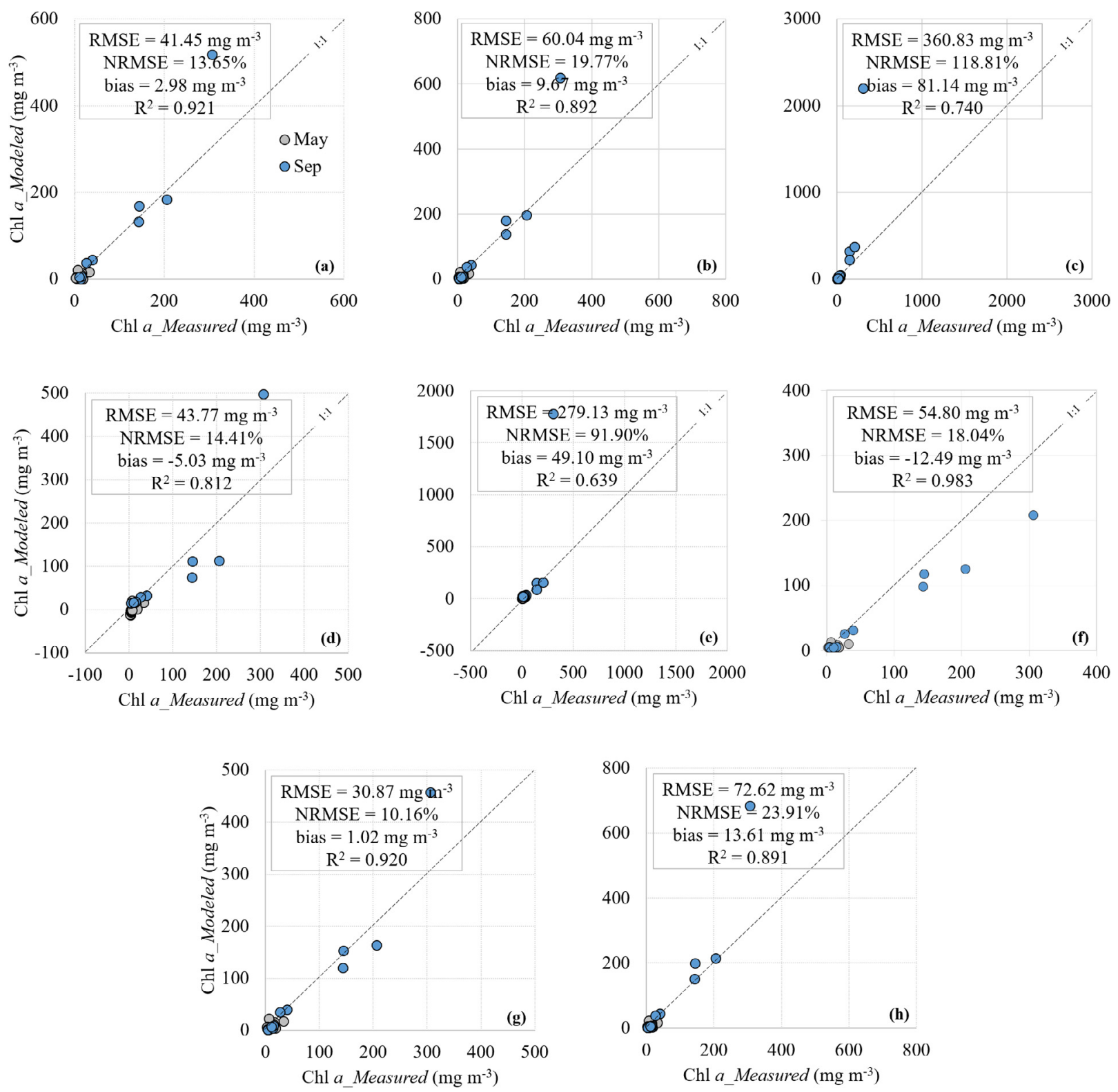

Fig. 4. Validation of existing algorithms using calibration parameters on the basis of RMSE $\left(\mathrm{mg} \mathrm{m}^{-3}\right)$, NRMSE $(\%)$, bias $\left(\mathrm{mg} \mathrm{m}^{-3}\right)$ and $\left(\mathrm{R}^{2}\right)$ for $(\mathrm{a}) 2 \mathrm{~B}-$ MO09, (b) 2B-GI10, (c) 2B-GU11, (d) 3B-MO09, (e) 3B-GU11, (f) NDCI-MI12, (g) SA-GO08 and (h) SA-GI10.

$\left.\mathrm{R}^{2}=0.89\right)$. Chl- $a$ range reported at 18 sampling stations and used by Moses et al. (2009) was from 0.63 to 65.61 $\mathrm{mg} \mathrm{m}^{-3}$, while Gilerson et al. (2010) adopted two thousand $R_{\mathrm{rs}}$ spectra simulated using Hydrolight, varying the chl $a$ concentration between 1 and $100 \mathrm{mg} \mathrm{m}^{-3}$. Although Gurlin et al. (2011) have used a chl $a$ range (2.3-200.8 $\mathrm{mg} \mathrm{m}^{-3}$ ) very similar to that reported in FHR, GU11 showed the poorest performance (NRMSE of $118.81 \%$ and a $\left.\mathrm{R}^{2}=0.74\right)$.

Considering the existing algorithms, overall, the insertion of a third band at $753.75 \mathrm{~nm}$ did not improve the chl $a$ estimation. Despite that, MO09 calibration for 3B algorithm exhibited the best performance in estimating chl $a$, with a NRMSE of $14.41 \%$ and a $\mathrm{R}^{2}$ of 0.81 . Taking to account just existing algorithms, NDCI-MI12 using second-degree polynomial exhibited performance similar to 3B (NRMSE of $18.04 \%$ and $\mathrm{R}^{2}$ of 0.98 ). Mishra and Mishra (2012) have used a synthetic dataset considering a chl $a$ range of $1-60 \mathrm{mg} \mathrm{m}^{-3}$.

Semi-analytical models also exhibited good results in predicting chl $a$ concentration. Actually, comparing all the tested algorithms, IIMIW (Li et al., 2013) based on GO10 algorithm (Gons et al., 2008) exhibited the lower error (NRMSE of $10.16 \%$ and $\mathrm{R}^{2}$ of 0.92 ). IIMIW was developed based on different turbid and productive inland waters. The researchers have used a dataset whose chl $a$ ranged from 1.85 to $285.80 \mathrm{mg} \mathrm{m}^{-3}$, i.e., very close to conditions found in the FHR. Although we do not have absorption data to compare with the absorption retrieved by IIMIW, it is assumed that the performance of semianalytical algorithms is directly related to quality of inherent optical properties used in parameterization. Therefore, 

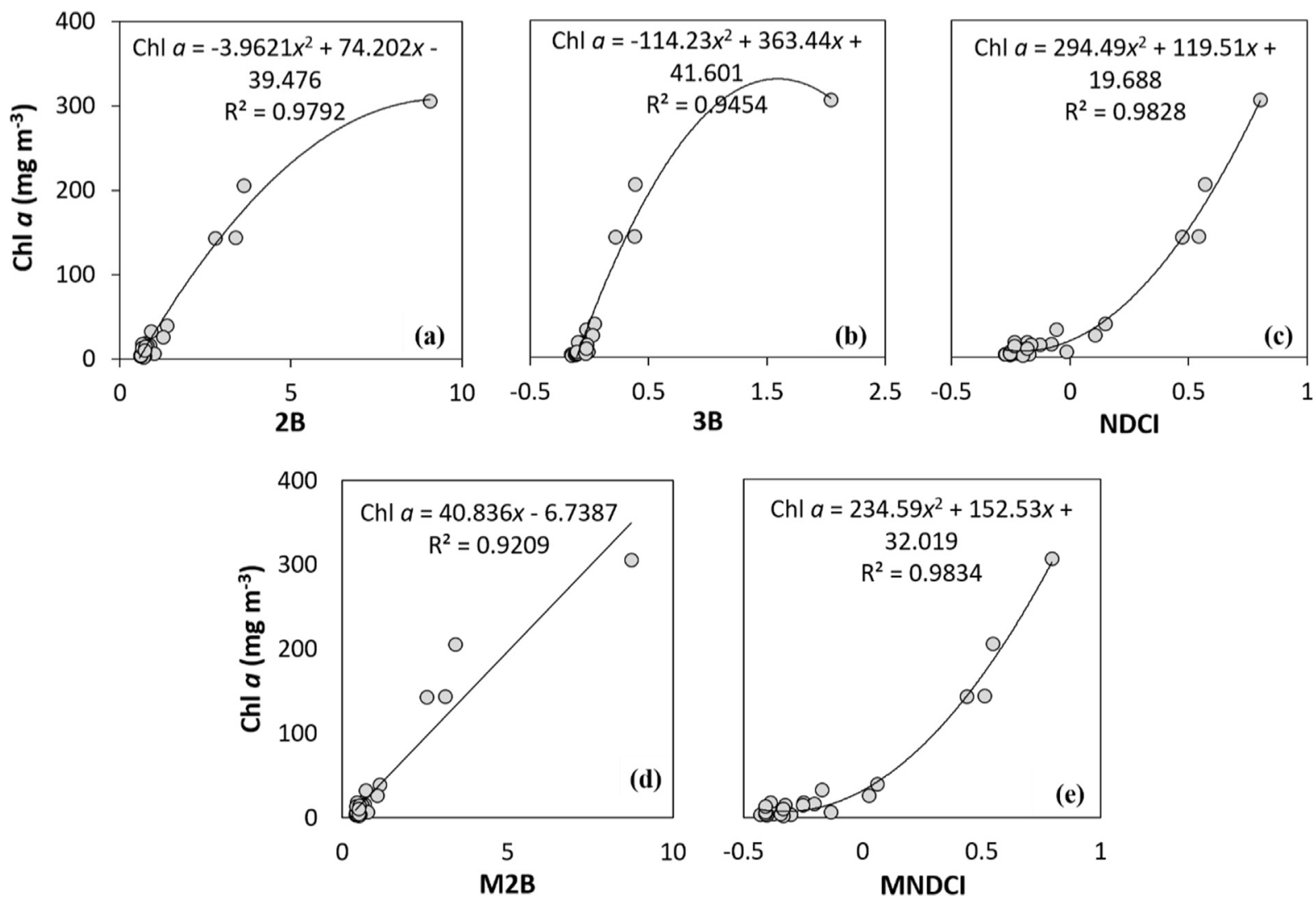

Fig. 5. Models fitted based on measurements collected in situ and spectral indexes: (a) 2B, (b) 3B, (c) NDCI, (d) M2B and MNDCI, using the OLCI band centered at 708.75 .

Table 2

Calibration coefficients $\left(\beta_{0}, \beta_{1}\right.$ and $\beta_{2}$ ) of the algorithms tuned for FHR using $665 \mathrm{~nm}$ (2B, 3B and NDCI) and 620 nm (M2B and MNDCI). Confidence interval of every coefficient determined by LOOCV is presented between parentheses.

\begin{tabular}{|c|c|c|c|c|}
\hline Model & $\beta_{2}$ & $\beta_{1}$ & $\beta_{0}$ & $p$-value \\
\hline $2 \mathrm{~B}$ & $\begin{array}{l}-3.9621 \\
(-4.6227 ; 7.6944)\end{array}$ & $\begin{array}{l}74.202 \\
(28.846 ; 80.695)\end{array}$ & $\begin{array}{l}-39.476 \\
(-43.743 ;-13.524)\end{array}$ & 0.000 \\
\hline $3 B$ & $\begin{array}{l}-114.23 \\
(-126.59 ; 401.48)\end{array}$ & $\begin{array}{l}363.44 \\
(253.48 ; 566.85)\end{array}$ & $\begin{array}{l}41.601 \\
(28.148 ; 43.616)\end{array}$ & 0.000 \\
\hline NDCI & $\begin{array}{l}294.49 \\
(196.79 ; 306.54)\end{array}$ & $\begin{array}{l}119.51 \\
(111.52 ; 129.6)\end{array}$ & $\begin{array}{l}19.688 \\
(17.579 ; 21.908)\end{array}$ & 0.000 \\
\hline M2B & $\begin{array}{l}- \\
-\end{array}$ & $\begin{array}{l}40.836 \\
(38.426 ;-60.686)\end{array}$ & $\begin{array}{l}-6.7387 \\
(21.467 ;-5.9881)\end{array}$ & 0.000 \\
\hline
\end{tabular}

the results obtained by semi-analytical algorithms indicate IIMIW worked suitability in retrieving absorption coefficient in FHR. Gons et al. (2008) designed their algorithms for oligotrophic and eutrophic inland waters, with chl $a$ ranging from 0.4 to $131 \mathrm{mg} \mathrm{m}^{-3}$ and even though the chl $a$ range is lower than our dataset, one of the lakes studied by the researchers has presented abundance of cyanobacteria as Funil reservoir.

\subsection{Parameterized and calibrated algorithms}

After testing some algorithms designed for productive inland waters, such algorithms were tuned using dataset collected in the FHR. Additionally, the wavelength at $620 \mathrm{~nm}$ was tested to retrieve chl $a$, due to phycocyanin absorption features observed in most $R_{\mathrm{rs}}$ spectra. The performance of these new algorithms was compared with their $650 \mathrm{~nm}$ counterparts. However, before a correlation analysis between OLCI Sentinel-3A plus the wavelength at $620 \mathrm{~nm}$ and the chl $a$ was conducted in order to show statistical relevance. The $R_{\mathrm{rs}}(708.75) / R_{\mathrm{rs}}(620)$ and $R_{\mathrm{rs}}(708.75) /$ $R_{\mathrm{rs}}(665)$ band ratios exhibited high correlation with such pigment ( $\mathrm{r}=0.892$ and $\mathrm{r}=0.891$, respectively). Fig. 5 shows the relationship among the different indexes and chl $a$ concentration. 

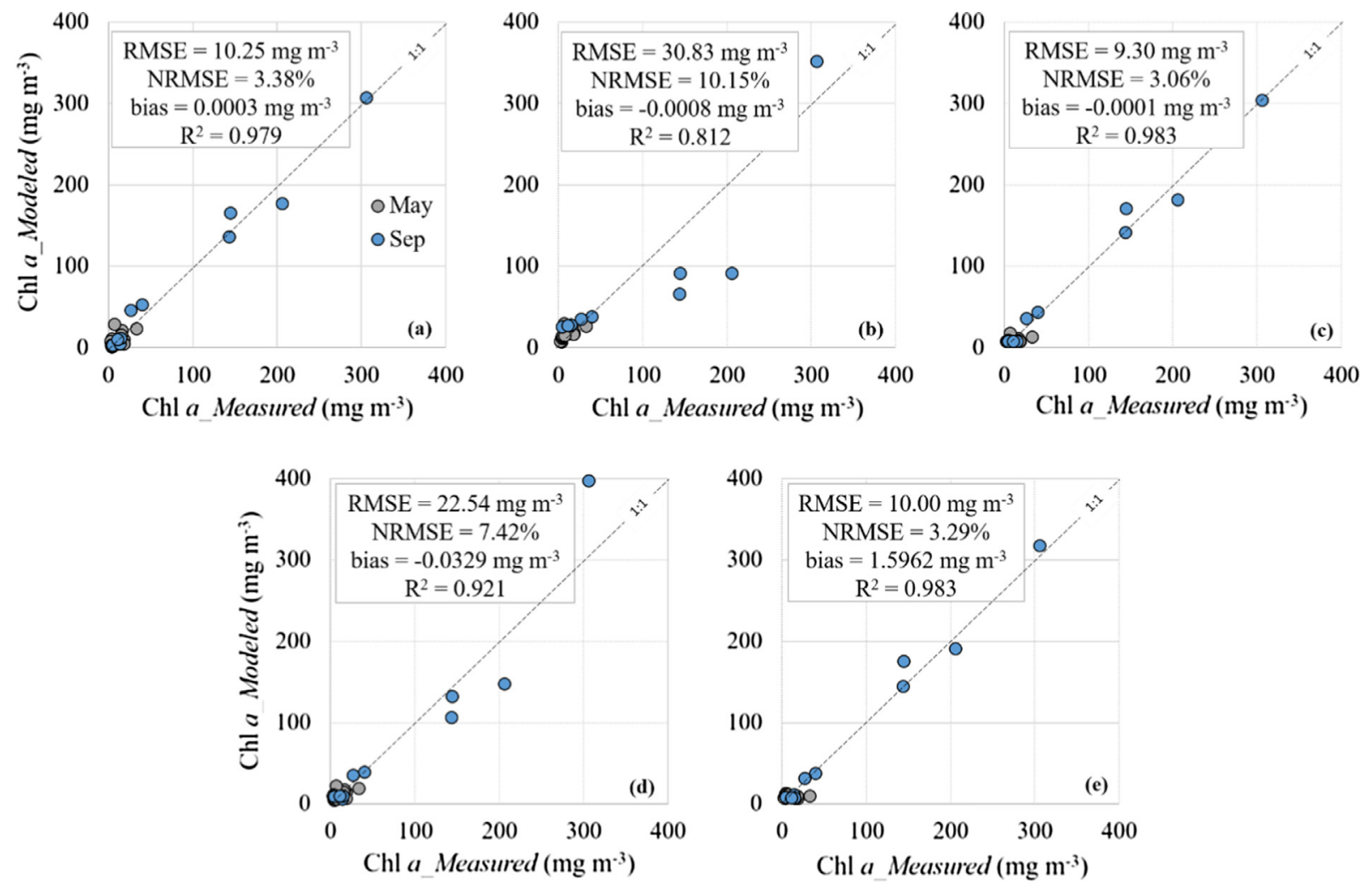

Fig. 6. Plots of measured versus modeled chl $a$ for tuned algorithms (a) 2B, (b) 3B, (c) NDCI as well as (d) M2B and (e) MNDCI fitted using 620 nm. Assessment of the algorithms was done based on RMSE $\left(\mathrm{mg} \mathrm{m}^{-3}\right)$, NMRSE (\%), bias $\left(\mathrm{mg} \mathrm{m}^{-3}\right)$ and $\mathrm{R}^{2}$.
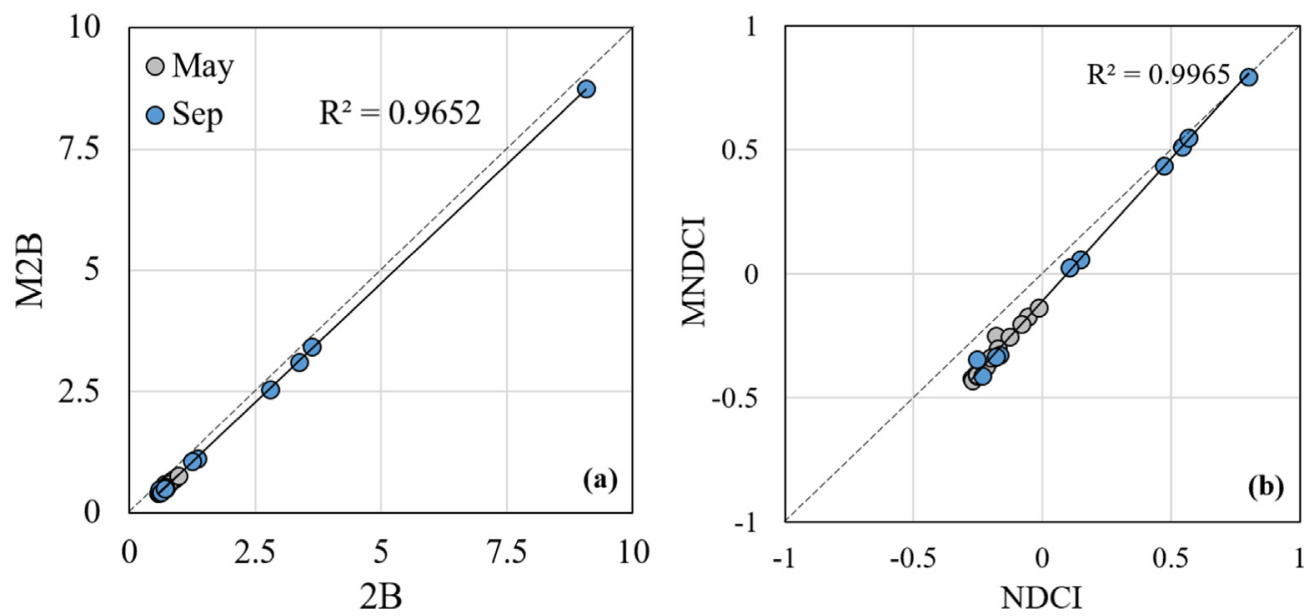

Fig. 7. Relationships between (a) 2B and M2B indexes and (b) NDCI and MNCI.

Table 2 shows the calibration coefficients obtained from the algorithms tuned for FHR using bands centered at 665 , 708.75 and $753.75 \mathrm{~nm}(2 \mathrm{~B}, 3 \mathrm{~B}$ and $\mathrm{NDCI})$ and 620 and $708.75 \mathrm{~nm}$ (M2B and MNDCI). In addition, it is presented the confidence interval of each coefficient determined from LOOCV. The validation has shown that all the algorithms tuned for FHR were statistically valid, since $\beta_{0}, \beta_{1}$ and $\beta_{2}$ were inserted within the 0.95 confidence interval.

Fig. 6 shows plots of measured versus modeled chl $a$ for new and tuned algorithms. All the algorithms fitted for
FHR have shown good performance, with low NRMSE and bias values. Among the tuned algorithms, NDCI index (polynomial fit) exhibited the best performance (NRMSE $=3.06 \%$ and $\mathrm{R}^{2}=0.983$ ), followed by MNDCI calibrated for FHR (NRMSE $=3.29 \%$ and $\mathrm{R}^{2}=0.983$ ). The paired $t$ test showed that NDCI and MNDCI were statistically equal. Therefore, there would be no impairment in replacing $\lambda_{2}$ from 620 to $665 \mathrm{~nm}$. The other algorithms exhibited similar performance, all of them not exceeding a NRMSE higher than $8 \%$. 


\section{Discussion}

The results obtained in this work showed that shifting the maximum phytoplankton absorption wavelength at red spectral region to longer wavelengths do not affect the chl $a$ estimation using $665 \mathrm{~nm}$. Comparing the algorithms with best performance, MNDCI with NDCI both calibrated for FHR using polynomial fit, they were considered statistically equal. Such results indicate that using either $665 \mathrm{~nm}$ or $620 \mathrm{~nm}$ present the same performance in estimating chl $a$ in cyanobacteria-dominated waters. Fig. 7 shows the strong relationship between $2 \mathrm{~B}$ and $\mathrm{M} 2 \mathrm{~B}$ indexes as well as NDCI and MNDCI indexes, with $\mathrm{R}^{2}$ close to 1 . In other words, analogous indexes were proportional, indicating there is no statistical difference in adopting either $620 \mathrm{~nm}$ or $665 \mathrm{~nm}$. Furthermore, the results showed that OLCI Sentinel-3A bands are capable of retrieving chl $a$ concentration accurately in cyanobacteria-dominated inland waters.

\section{Conclusion}

Considering the results obtained in this present research we concluded that NIR-red and SA algorithms are not impaired by shifting the maximum chl $a$ absorption peak in the red spectral region. Both NIR-red and SA algorithms exhibited accurate performance in estimating chl $a$ in FHR. Additionally, the OLCI Sentinel-3A data were rather suitable to estimate chl $a$ content, encouraging its use in water quality monitoring. Bands centered at $665 \mathrm{~nm}$ and $709 \mathrm{~nm}$ were suitable to retrieve chl $a$ in cyanobacteria-dominated waters, in spite of the maximum absorption by chl $a$ is shifted at longer wavelengths around $680 \mathrm{~nm}$. We have also verified that the use of $665 \mathrm{~nm}$ or $620 \mathrm{~nm}$ did not change remarkably the performance of M2B and MNDCI algorithms. The strong relationship between $\mathrm{M} 2 \mathrm{~B}$ and $2 \mathrm{~B}$ ratios showed that both ratios are directly proportional and, therefore, they would produce similar results. Among the tested and recalibrated algorithms, NDCI index exhibited the best performance. Its structure was capable of highlighting the difference between chl $a$ absorption in the red region and particles reflectance around $708.75 \mathrm{~nm}$. Surprisingly, the SA algorithm presented better performance than the some existing band algorithms, even fitted to other aquatic systems. Although it has not been possible to evaluate the performance of IIMIW in estimating the inherent optical properties, the results indicated that the prediction of chl $a$ was accurate, with the best performance among the tested existing algorithms using GO10 (NRMSE of $10.16 \%$ ). Such algorithm used the wavelength at $665 \mathrm{~nm}$, showing the efficiency of that spectral region in retrieving chl $a$ content. Taking into account the findings in this research, more studies should be carried out in other cyanobacteria-dominated aquatic systems, especially, in relation to $\mathrm{SA}$.

\section{Acknowledgments}

The authors thank to Fundação de Amparo à Pesquisa do Estado de São Paulo (FAPESP N ${ }^{\circ}$ 2011/19523-8 and 2015/18525-8) and National Council of Technological and Scientific Development (CNPq $\mathrm{N}^{\circ}$ 471223/2011-5) for financial support under grants.

\section{References}

Anderson, D.M., Gilbert, P.M., Burkholder, J.M., 2002. Harmful algal blooms and eutrophication: nutrients sources, composition, and consequences. Estuaries 25 (4), 704-726. https://doi.org/10.1007/ BF02804901.

APHA, 1998. Standard Methods for the Examination of Water and Wastewater, 20th ed. American Public Health Association (APHA), American Water Works Association (AWWA), Water Environmental Federation (WEF), Washington, DC.

Bernardo, N., Watanabe, F., Rodrigues, T., Alcântara, E., 2017. Atmospheric correction issues for retrieving total suspended matter concentrations in inland waters using OLI/Landsat- 8 image. Adv. Space Res. 59 (9), 2335-2348. https://doi.org/10.1016/j. asr.2017.02.017.

Calijuri, M.C., dos Santos, A.C.A., 1996. Short-term changes in the Barra Bonita reservoir (São Paulo, Brazil): emphasis on the phytoplankton communities. Hydrobiologia 330, 163-175. https://doi.org/10.1007/ BF00024205.

Carder, K.L., Chen, F.R., Lee, Z.P., Hawes, S.K., Kamykowski, D., 1999. Semi-analytic Moderate-Resolution Imaging Spectrometer algorithms for chlorophyll a and absorption with bio-optical domains based on nitrate-depletion temperatures. J. Geophys. Res. 104, 5403-5422. https://doi.org/10.1029/1998JC900082.

Carvalho, L., Miller, C.A., Scott, E.M., Codd, G.A., Davies, O.S., Tyler, A.N., 2011. Cyanobacteria blooms: statistical models describing risk factors for national-scale lake assessment and lake management. Sci. Total Environ. 409, 5353-5358. https://doi.org/10.1016/j. scitotenv.2011.09.030.

Costa, S.M., Appel, E., Macedo, C.F., Huszar, V.L.M., 2014. Low water quality in tropical fishponds in southern Brazil. Anais Acad. Brasileira Ciências 86 (3), 1181-1195. https://doi.org/10.1590/00013765201420130092.

Dall'Olmo, G., Gitelson, A.A., Rundquist, D.C., 2003. Towards a unified approach for remote estimation of chlorophyll-a in both terrestrial vegetation and turbid productive waters. Geophys. Res. Lett. 30 (18), 1938. https://doi.org/10.1029/2003GL018065.

Dekker, A., 1993. Detection of the Optical Water Quality Parameters for Eutrophic Waters by High Resolution Remote Sensing (PhD diss). Vrije Universiteit.

Gilerson, A.A., Gitelson, A.A., Zhou, J., Gurlin, D., Moses, W., Ioannou, I., Ahmed, S.A., 2010. Algorithms for remote estimation of chlorophyll- $a$ in coastal and inland waters using red and near infrared bands. Opt. Express 18 (23), 24109-24125. https://doi.org/10.1364/ OE.18.024109.

Gons, H.J., Auer, M.T., Effler, S.W., 2008. MERIS satellite chlorophyll mapping of oligotrophic and eutrophic waters in the Laurentian Great Lakes. Remote Sens. Environ. 112, 4098-4106. https://doi.org/ 10.1016/j.rse.2007.06.029.

Gurlin, D., Gitelson, A.A., Moses, W.J., 2011. Remote estimation of chl-a concentration in turbid productive waters - return to a simple twoband NIR-red model? Remote Sens. Environ. 115, 3479-3490. https:// doi.org/10.1016/j.rse.2011.08.011.

Li, L., Li, L., Song, K., Li, Y., Tedesco, L.P., Shi, K., Li, Z., 2013. An inversion model for deriving inherent optical properties of inland waters: establishment, validation and application. Remote Sens. Environ. 135, 150-166. https://doi.org/10.1016/j.rse.2013.03.031. 
Mishra, D., Mishra, S., 2010. Plume and bloom: effect of the Mississippi River diversion on the water quality of Lake Pontchartrain. Geocarto Int. 25, 555-568. https://doi.org/10.1080/10106041003763394.

Mishra, S., Mishra, D.R., 2012. Normalized difference chlorophyll index: a novel model for remote estimation of chlorophyll-a concentration in turbid productive waters. Remote Sens. Environ. 117, 394-406. https://doi.org/10.1016/j.rse.2011.10.016.

Mishra, S., Mishra, D.R., Lee, Z.P., 2014. Bio-optical inversion in highly turbid and cyanobacteria-dominated waters. IEEE Trans. Geosci. Remote Sens. 52 (1), 375-388. https://doi.org/10.1109/ TGRS.2013.2240462.

Mobley, C.D., 1999. Estimation of the remote-sensing reflectance from above-surface measurements. Appl. Opt. 38 (36), 7442-7455. https:// doi.org/10.1364/AO.38.007442.

Moses, W.J., Gitelson, A.A., Berdnikov, S., Povazhnyy, V., 2009. Satellite estimation of chlorophyll-a concentration using the red and NIR bands of MERIS - the Azov Sea case study. IEEE Geosci. Remote Sens. Lett. 6 (4), 845-849. https://doi.org/10.1109/ LGRS.2009.2026657.

Nusch, E.A., 1980. Comparison of different methods for chlorophyll and phaeopigment determination. Arch. Hydrobiol.-BeiheftErgebnisse Limnol. 14, 14-36.

Ogashawara, I., Mishra, D.R., Mishra, S., Curtarelli, M.P., Stech, J.L., 2013. A performance review of reflectance based algorithms for predicting phycocyanin concentrations in inland waters. Remote Sens. 5, 4774-4798. https://doi.org/10.3390/rs5104774.

Olmanson, L.G., Brezonik, P.L., Bauer, M.E., 2013. Airborne hyperspectral remote sensing to assess spatial distribution of water quality characteristics in large rivers: the Mississippi River and its tributaries in Minnesota. Remote Sens. Environ. 2013, 254-265. https://doi.org/ 10.1016/j.rse.2012.11.023.

Rangel, L.M., Silva, L.H.S., Rosa, P., Roland, F., Huszar, V.L.M., 2012. Phytoplankton biomass is mainly controlled by hydrology and phosphorus concentrations in tropical hydroelectric reservoirs. Hydrobiologia 693, 13-28. https://doi.org/10.1007/s10750-012-1083-3.

Richardson, L.L., 1996. Remote sensing of algal bloom dynamics: new research fuses remote sensing of aquatic ecosystems with algal accessory pigment analysis. Bioscience 46 (7), 492-501.
Ritchie, R.J., 2008. Universal chlorophyll equations for estimating chlorophylls a, b, c, and $\mathrm{d}$ and total chlorophylls in natural assemblages of photosynthetic organisms using acetona, methanol, or ethanol solvents. Photosynthetica 46, 115-126, https://doi.org/10. 1007\%2Fs11099-008-0019-7.

Romo, S., Soria, J., Fernández, F., Ouahid, Y., Barón-Solá, A., 2013. Water residence time and the dynamics of toxic cyanobacteria. Freshwater Biol. 58, 513-522. https://doi.org/10.1111/j.13652427.2012.02734.x.

Ruiz-Verdú, A., Simis, S.G.H., de Hoyos, C., Gons, H.J., Peña-Martínez, R., 2008. An evaluation of algorithms for the remote sensing of cyanobacterial biomass. Remote Sens. Environ. 112, 3996-4008. https://doi.org/10.1016/j.rse.2007.11.019.

Schalles, J.F., Yacobi, Y.Z., 2000. Remote detection and seasonal patterns of phycocyanin, carotenoids and chlorophyll pigments in eutrophic waters. Arch. Hydrobiol. 55, 153-168.

Shi, K., Zhang, Y., Li, Y., Li, L., Lv, H., Liu, X., 2015. Remote estimation of cyanobacteria-dominance in inland waters. Water Res. 68, 217-226. https://doi.org/10.1016/j.watres.2014.10.019.

Soares, M.C.S., Marinho, M.M., Huszar, V.L.M., Branco, C.W.C., Azevedo, S.M.F.O., 2008. The effects of water retention time and watershed features on the limnology of two tropical reservoirs in Brazil. Lakes Reserv.: Res. Manage. 13, 257-269. https://doi.org/ 10.1111/j.1440-1770.2008.00379.x.

Soares, M.C.S., Marinho, M.M., Azevedo, S.M.O.F., Branco, C.W.C., Huszar, V.L.M., 2012. Eutrophication and retention time affecting spatial heterogeneity in a tropical reservoir. Limnologica 42, 197-203. https://doi.org/10.1016/j.limno.2011.11.002.

Tan, J., Cherkauer, K.A., Chaubey, I., 2015. Using hyperspectral data to quantify water quality parameters in the Wabash River and its tributaries, Indiana. Int. J. Remote Sens. 36 (21), 5466-5484. https:// doi.org/10.1080/01431161.2015.1101654.

Watanabe, F.S.Y., Alcântara, E., Rodrigues, T.W.P., Imai, N.N., Barbosa, C.C.F., Rotta, L.H.S., 2015. Estimation of chlorophyll-a concentration and the trophic state of the Barra Bonita hydroelectric reservoir using OLI/Landsat-8 images. Int. J. Environ. Res. Public Health 12 (9), 10391-10417. https://doi.org/10.3390/ijerph120910391. 